\title{
Liver retraction techniques for laparoscopic cholecystectomy
}

We read with interest the article by Sekimoto et al. in the December 1998 issue of Surgical Endoscopy [6]. We were somewhat surprised to see the liver retraction technique described as "new" since it was previously published in this Journal in 1995 [2] and later illustrated in a 1996 article [3]. It has been in routine use in our Leeds clinic since 1991 .

We use Diamond-Flex retractors (Genzyme Surgical Products, Tucker, GA, USA), which were developed specifically for liver retraction during laparoscopic cholecystectomy. These are malleable retractors which, when inserted through a $5-\mathrm{mm}$ cannula, are tightened to produce a predefined shape. The retractors have a rounded profile and can be placed under the liver without causing trauma [Fig. 1].

We agree with the authors' observation that the technique allows good exposure of the undersurface of the liver. It also avoids distortion of Calot's triangle caused by fundal traction [5]. The retractors were developed in accordance with a principle established earlier at open cholecystectomy-namely, they are designed to open the angle between the cystic duct and bile duct. Other shapes of retractor are available to cope with a large quadrate lobe. We have now employed this method of retraction in $>1,000$ laparoscopic cholecystectomies, with a conversion rate of $0.5 \%$ during the last 2 years. Despite an "all-comers" policy since the introduction of the procedure to our unit [4], there have been no deaths and no bile duct injuries.

We disagree with the Osaka group over the use of the reverse Trendelenburg position when the retractor is employed. We routinely use low-pressure insufflation (7 $\mathrm{mmHg}$ ) and find the exposure to be more than adequate in most cases. Should intraabdominal fat obscure the view, we routinely insert an additional retractor through a $5-\mathrm{mm}$ cannula placed in the left upper quadrant to hold down the fat. The dangers associated with capnoperitoneum and the reverse Trendelenburg position were recently highlighted in The Report of the National Confidential Enquiry into Perioperative Deaths 1996/1997 (NCEPOD) [1]. We believe that maintenance of the supine position with low pressure reduces the physiological insult [7], especially among patients who are elderly and have poor cardiorespiratory function. The lower pressure also reduces postoperative pain [8].

The liver retractor obviates the need for traction to be applied to the fundus of the gallbladder to gain exposure; it also permits a fundus-first technique of dissection to be employed when needed [2]. This technique confers an invaluable advantage in difficult cholecystectomies, and we have no doubt that it has contributed to our low conversion rate.

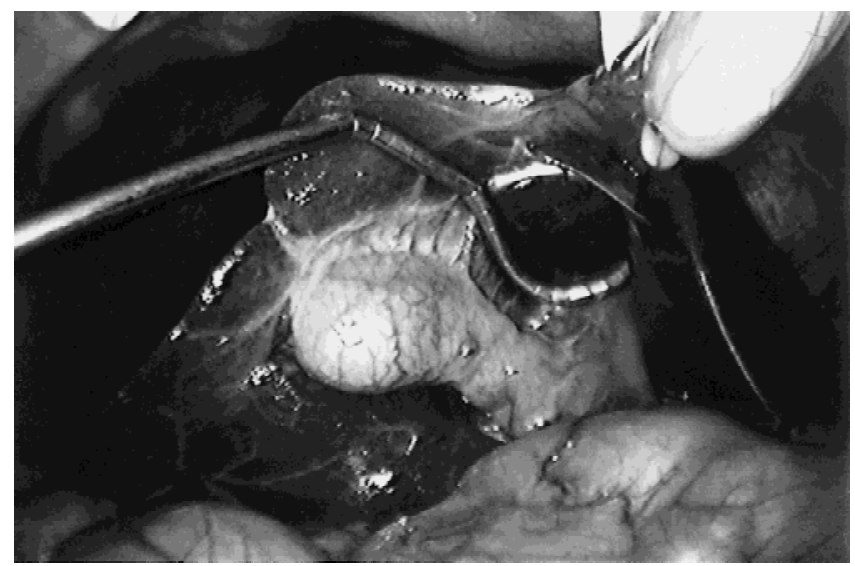

Fig. 1. A Diamond-Flex retractor being used to elevate the liver during laparoscopic cholecystectomy.

\section{References}

1. Gray AJG, Hoile RW, Ingram GS, Sherry KM (1998) The report of the National Confidential Enquiry into Perioperative Deaths 1996/1997. NCEPOD.

2. Martin IG, Dexter SPL, Marton J, Gibson J, Asker J, Firullo A, McMahon MJ (1995) Fundus-first laparoscopic cholecystectomy. Surg Endosc 9: 203-206

3. Martin IG, Dexter SPL, McMahon MJ (1996) Laparoscopic cholecystectomy in pregnancy: a safe option during the second trimester? Surg Endosc 10: 508-510

4. Martin IG, Holdsworth PJ, Asker J, Baltas B, Glinatsis MT, Sue-Ling H, Gibson J, Johnston D, McMahon MJ (1992) Laparoscopic cholecystectomy as a routine procedure for gallstones: results of an "allcomers" policy. Br J Surg 79: 807-810

5. McIntyre Jr RC, Bensard DD, Stiegmann GV, Pearlman NW, Durham J (1996) Exposure for laparoscopic cholecystectomy dissection adversely alters biliary ductal anatomy. Surg Endosc 10: 41-43

6. Sekimoto M, Tomita N, Tamura S, Ohsato H, Monden M (1998) New retraction technique to allow better visualisation of Calot's triangle during laparoscopic cholecystectomy. Surg Endosc 12: 1439-1441

7. Wahba RWM, Beique F, Kleiman SJ (1995) Cardiopulmonary function and laparoscopic cholecystectomy. Can J Anaesth 42: 51-63

8. Wallace DH, Serpell MG, Baxter JN, O’Dwyer PJ (1997) Randomized trial of different insufflation pressures for laparoscopic cholecystectomy. Br J Surg 84: 455-458

\section{W. G. Ainslie}

M. Larvin

I. G. Martin

M. J. McMahon

Leeds Institute for Minimally Invasive Theraphy (LIMIT)

The University Division of Surgery

$6^{\text {th }}$ Floor, Wellcome Wing

General Infirmary

Great George Street

Leeds, England LS1 3EX 